engaged in substance abuse and sexual behaviours that increase their risk of HIV transmission, and STD transmission and acquisition. Such patients were more likely to want to discuss their mental health concerns than those who did not engage in these behaviours. These findings underscore the importance of interventions to decrease risky sexual behaviour and to promote clinical assessment of mental health needs for this patient population. A mental health assessment can identify patients who might need greater psychosocial support or referral for treatment of substance abuse and underlying mental illness.

\section{P5-S1.03 HIV STATUS DISCLOSURE IN FAMILY AND DETERMINANTS OF STIGMATISATION IN A CONSERVATIVE SOCIETY}

doi:10.1136/sextrans-2011-050108.532

${ }^{1}$ A Rashid, ${ }^{2}$ M Adnan. ${ }^{1}$ PMAS Arid Agriculture University, Rawalpindi, Pakistan; ${ }^{2}$ F.G. Postgraduate College (Men), Rawalpindi, Pakistan

Background National AIDS control of Pakistan and its development partner Canadian Government CIDA is seeking for effective AIDS surveillance. However, prevailing illiteracy and conservative societal norms are challenging factors in preventing HIV spread. Factors which lead to behavioural changes among people if they have been told of their HIV positive status are complicated and directly related to self-esteem and personal liberation.

Methods We evaluated this complex phenomenon with an aim to identify factors that prevent a person to disclose his/her HIV status to family members. Effort was also made to characterise determinants of prevailing stigma at society level for HIV positive and PLHA. Self structured questionnaire with binary and multiple response items was used for data collection. Multivariate logistic regression was used to identify significant predictors of stigma at family and societal level.

Results A total of 412 subjects (178 females and 234 males) were included in the study. Family level anticipated stigma items that were significantly associated with HIV test refusal were family perception, life partner perception, family break-up and neglect by family. Social indicators for prevalent stigmatisation were losing job and livelihood, bad treatment by the healthcare worker and difficulty in finding marital partner of choice (Abstract P5-S1.03 table 1). Conclusions The study concludes that prevailing stigma is the major hindrance for running effective AIDS surveillance program. Clinical programs to prevent HIV infection must be integrated with psychiatric care service as a policy to improve awareness and peoples' willingness for HIV testing.

Abstract P5-S1.03 Table 1 Association of HIV stigma with test refusal at personal level as predictors of family and social stigmatisation

\begin{tabular}{llll}
\hline $\begin{array}{l}\text { Dependent variable } \\
\text { Family level stigma indicators }\end{array}$ & $\begin{array}{l}\text { Adjusted OR for HIV } \\
\text { test refusal }\end{array}$ & $\mathbf{9 5 \%} \mathbf{~ C l}$ & p Value \\
$\quad$ Life partner perception & 2.15 & & \\
$\quad$ Family perception & 1.42 & 0.92 to 3.64 & $<0.001$ \\
$\quad$ Family break-up & 1.16 & 1.12 to 2.85 & $<0.01$ \\
$\quad$ Neglect by family & 1.83 & 1.02 to 2.88 & $<0.05$ \\
Social stigma indicators & & 1.32 to 2.41 & $<0.01$ \\
$\quad$ Losing job & 1.72 & & \\
$\quad$ Livelihood loss & 1.05 & 1.22 to 3.74 & $<0.01$ \\
$\quad$ Health worker treatment & 1.22 & 0.29 to 0.65 & $<0.001$ \\
Marital life entry fallout & 2.41 & 1.23 to 4.67 & $<0.05$ \\
\hline
\end{tabular}

\section{P5-S1.04 THE IMPACT OF PELVIC INFLAMMATORY DISEASE ON SEXUAL, REPRODUCTIVE AND PSYCHOLOGICAL HEALTH}

doi:10.1136/sextrans-2011-050108.533

${ }^{1} \mathrm{~J}$ Hocking, ${ }^{1} \mathrm{D}$ Newton, ${ }^{2} \mathrm{C}$ Bayly, ${ }^{3} \mathrm{C}$ Fairley, ${ }^{3} \mathrm{M}$ Chen, ${ }^{3} \mathrm{H}$ Williams, ${ }^{1} \mathrm{~L}$ Keogh, ${ }^{1} \mathrm{M}$ Temple-Smith, ${ }^{4} \mathrm{~K}$ McNamee, ${ }^{1} \mathrm{~J}$ Fisher, ${ }^{1} \mathrm{~A}$ Hsueh, ${ }^{1} \mathrm{~J}$ Hocking. ${ }^{1}$ University of Melbourne, Melbourne, Australia; ${ }^{2}$ The Royal Women's Hospital, Melbourne, Australia, ${ }^{3}$ Melbourne Sexual Health Centre, Sexual Health Unit, School of Population Health, University of Melbourne, Australia; ${ }^{4}$ Family Planning Victoria, Australia

Background and Aim Pelvic inflammatory disease (PID) is a condition commonly attributable to chlamydia infection. This qualitative study sought to explore the sexual, reproductive and psychological impact of this condition.

Methods In depth, semi-structured interviews were conducted with 23 women diagnosed with PID. Both symptomatic and asymptomatic women were recruited from primary and tertiary healthcare services. Interviews were conducted with women from 2 to 12 months post-diagnosis in order to explore short and longer term psychological responses and experiences. A brief, self-report questionnaire containing demographic items was also completed by all women. Interview analysis was conducted using an inductive, thematic approach.

Results Nearly all women experienced some form of distress when they received their diagnosis, and the emotional impact of their diagnosis was generally prolonged. Women typically experienced emotions such as shock, sadness or anger. At the time of diagnosis, women frequently had little or no knowledge of PID and continued to experience confusion about their condition post-diagnosis. Some women reported that PID had created conflict in their intimate relationships or had impacted on the level of intimacy they shared with their partner. Almost all women reported that their sexual behaviour had changed dramatically post- diagnosis. The possibility of being infertile stood out for women as their greatest health concern and nearly all women reported changes to their health behaviours since their diagnosis.

Conclusion The findings of this study indicate that a diagnosis of PID can have significant psychosocial implications for the diagnosed individual. Recommendations for healthcare professionals are proposed.

\section{Health services and policy poster session 2: Circumcision \\ P5-S2.01 SURVEY ON KNOWLEDGE, ATTITUDE AND PRACTICES ON MALE CIRCUMCISION IN RWANDA}

doi:10.1136/sextrans-2011-050108.534

J Mbabazi. TRACPlus, Kigali, Rwanda

Background WHO/Joint United Nations Program on AIDS (UNAIDS) has recommended adult male circumcision (AMC) for the prevention of heterosexually acquired HIV infection in men from communities where HIV is hyper endemic and AMC prevalence is low. The aim of this study was to provide evidences on knowledge and attitudes of non-circumcised men with regard to $\mathrm{MC}$, and to determine the willingness to be circumcised among Rwandan men aged $15-59$ years.

Methods This cross sectional study was part of a large survey conducted in Rwanda in January 2010 by the Ministry of Health, to assess knowledge, attitudes and practices regarding $\mathrm{MC}$ in the general population (KAP). The data were collected independent of religions and participants were recruited from all of the five provinces of Rwanda and 29 out of 30 districts were covered The data were 